Beata JAGIEŁA ${ }^{1}$

Marek GOSZTYLA ${ }^{2}$

\title{
PROJEKTY KONSERWATORSKIE ZYGMUNTA HENDLA W KOŚCIELE OO. BERNARDYNÓW W RZESZOWIE
}

\begin{abstract}
Dokonania Hendla poprzedzające prace konserwatorskie przy zespole OO. Bernardynów w Rzeszowie, a także piastowane przezeń stanowisko konserwatora okręgu tarnowsko - rzeszowskiego stanowiły najlepszą legitymację architekta i były powodem zatrudnienia go jako kierownika prac przy zespole OO. Bernardynów w Rzeszowie. Jak wynika z zachowanych projektów - było to wymagające i zakrojone na dużą skalę przedsięwzięcie. Hendel łączył w swej działalności zawodowej badania i konserwacje zabytków architektury z twórczością architektoniczną. Najczęściej wypowiadał się w formach eklektyzmu. Część jego licznych projektów nigdy nie doczekała się realizacji na skutek splotu różnych okoliczności. W pacach przy obiektach zabytkowych przeważał kierunek restauracji, przy dość szerokim zróżnicowaniu rodzaju i stopnia ingerencji - od powściągliwych, ograniczonych uzupełnień substancji zabytkowej (poddanej zabiegom konserwatorskim na miarę ówczesnego stanu wiedzy i rozwoju technologii) do zasadniczej przebudowy i rozbudowy obiektu.

Poniżej przedstawiono ważniejsze $\mathrm{z}$ działań konserwatorskich i projektowych oraz ich specyfikę.

Opis projektów będących przedmiotem koncepcji restauracji zespołu OO. Bernardynów w Rzeszowie, zarówno tych, które doczekały się realizacji, jak i tych, które nie zrealizowano, autorzy omawiają na przykładzie ołtarza Świętego Krzyża, tabernakulum w kaplicy Matki Bożej Rzeszowskiej, mensy ołtarzowej w kaplicy Matki Bożej Rzeszowskiej, konfesjonałów. Omówiony został również projekt witraża. Celem opracowania jest próba analizy przyjmowanych koncepcji restauracji zespołu OO. Bernardynów w Rzeszowie autorstwa krakowskiego architekta - Zygmunta Hendla. Pogłębiona charakterystyka projektów konserwatorskich z I dekady XX wieku, przeprowadzona została w oparciu o dokumentację projektową pochodzącą ze zbiorów Muzeum Narodowego w Krakowie. Pozwoli to w sposób istotny pogłębić wiedzę tak w zakresie historii omawianego zabytku, jak i historii rozwoju konserwacji zabytków na ziemiach Galicji w okresie autonomii.
\end{abstract}

Słowa kluczowe: zabytek architektury, kościól, klasztor, architekt, konserwacja zabytków, autonomia galicyjska

\footnotetext{
${ }^{1}$ Autor do korespondencji: dr Beata Jagieła, starszy wykładowca w Państwowej Wyższej Szkole Techniczno - Ekonomicznej w Jarosławiu, adres zamieszkania: ul. Polna 10/2, 37-500 Jarosław, tel. 798400009, beata.jagiela@op.pl

${ }^{2}$ dr hab. inż. prof. PRz. Marek Gosztyła, kierownik Katedry Konserwacji Zabytków na Politechnice Rzeszowskiej, tel. 17865 1939, gosztyla@prz.edu.pl
} 


\section{Wstęp}

W prezbiterium Bazyliki OO. Bernardynów w Rzeszowie rozmieszczono pomniki pośmiertne przedstawicieli rodu Ligęzów datowane na I poł. XVII wieku, którzy zaliczani są do fundatorów świątyni. Są to pomniki manierystyczne będące najprawdopodobniej dziełem Sebastiana Sali. W niszach prezbiterium umieszczone zostały symetrycznie zgrupowane po cztery w dwóch rzędach sylwetki klęczących mężczyzn naturalnej wielkości wykonane z mlecznego alabastru. Siedem $z$ nich to rycerze $w$ renesansowych zbrojach, natomiast ósma przedstawia biskupa w szatach pontyfikalnych. Pod niszami umieszczono tablice inskrypcyjne z czarnego marmuru. To bardzo eleganckie zestawienie bieli alabastru z kontrastową czernią stanowi, oprócz niezaprzeczalnych wartości rzeźbiarskich figur, o klasie tego zabytku.

W kaplicy Matki Boskiej Rzeszowskiej znajduje się, umieszczona w środkowej części retabulum, słynąca cudami figura Matki Boskiej z Dzieciątkiem o późnogotyckim rodowodzie, powstała około 1475 roku. ${ }^{3}$ Niezwykle piękną, wykonaną $\mathrm{z}$ drewna i polichromowaną rzeźbę przyoblekają barokowe szaty: suknia i płaszcz spływające bogactwem ozdób. Głowę Maryi wieńczy barokowa korona wykonana ze złoconego srebra, będąca perełką jubilerskiej roboty. Po bokach retabulum widnieją barokowe obrazy olejne z połowy XVIII wieku przedstawiające sceny z życia Maryi. Wnętrze kaplicy, podobnie jak i wnętrze całej świątyni, pokrywa rokokowa polichromia z połowy XVIII wieku autorstwa Antoniego Szulca z Warszawy oraz Tomasza i Krzysztofa Kędzierskich z Rzeszowa [3;7].

Ołtarz Świętego Krzyża, znajdujący się obecnie w korytarzu łączącym kościół z klasztorem jest bez wątpienia jednym z najważniejszych zabytków rzeszowskiego kościoła bernardyńskiego. Został on wykonany przy użyciu czarnego marmuru oraz mlecznego alabastru użytego do wykonania elementów detalu architektonicznego. Centralną część ołtarza stanowi arkadowa płycina, w którą wkomponowano krzyż. Ołtarzowi towarzyszyły niegdyś dwie figury: Matki Bożej Bolesnej oraz św. Jana. Pod ołtarzem znajdują się doczesne szczątki fundatorów sanktuarium, o czym informuje tablica $\mathrm{z}$ inwokacją i wspomnieniem o fundacji Mikołaja Spytka Ligęzy usytuowana w dolnej części ołtarza. Na gzymsach po lewej i prawej stronie znajdują się rzeźby geniuszów śmierci. Autorem dzieła jest najprawdopodobniej wytrawny rzeźbiarz: Sebastian Sala, nie należy się więc dziwić temu, że ołtarz zwrócił uwagę Zygmunta Hendla, który na marginesach swego rysunku umieścił lapidarne notki dotyczące zaginionych figur.

Początek XX wieku należy łączyć z rozpoczęciem prac projektowych w zespole OO. Bernardynów w Rzeszowie przez Z. Hendla.

\footnotetext{
${ }^{3}$ W 1763 roku cudowną figurę koronowano.
} 


\section{Hendlowska koncepcja restauracji}

Opis projektów związanych z restauracja zespołu OO. Bernardynów w Rzeszowie, zarówno tych, które zrealizowano jak i tych, które nie doczekały się z różnych względów realizacji - zaczniemy od bardzo ciekawego projektu dotyczącego restauracji ołtarza Świętego Krzyża.

W zbiorach Muzeum Narodowego w Krakowie zachował się projekt restauracji niniejszego ołtarza (rys.1). Co ciekawe, projekt ten zdaje się stanowić lustrzane odbicie istniejącej, oryginalnej realizacji, zakłada bowiem wprowadzenie okładzin z białego alabastru tam gdzie oryginalnie występuje czarny marmur i na odwrót. Biorąc pod uwagę fakt, że ubytki kamiennych elementów ołtarzy w czasach poprzedzających projektowaną renowację, łatano często nieprofesjonalnie, szpachlując je pośpiesznie kitami sens chęci wyposażenia ołtarza w nowe okładziny marmurowe i alabastrowe wydaje się zrozumiałym. Czyżby jednak tak daleko idąca ingerencja w kolorystykę ołtarza, być może podyktowana chęcią rozjaśnienia go, była zasadna? Jak się wydaje, musiano uznać, że nie, ołtarz bowiem jak wiemy nie został odnowiony w duchu śmiałego projektu Hendla.

Dodatkowo - według projektu krakowskiego architekta - geniusze śmierci mieli zostać umieszczeni na cokołach w partii szczytowej ołtarza - tak się jednak nie stało.

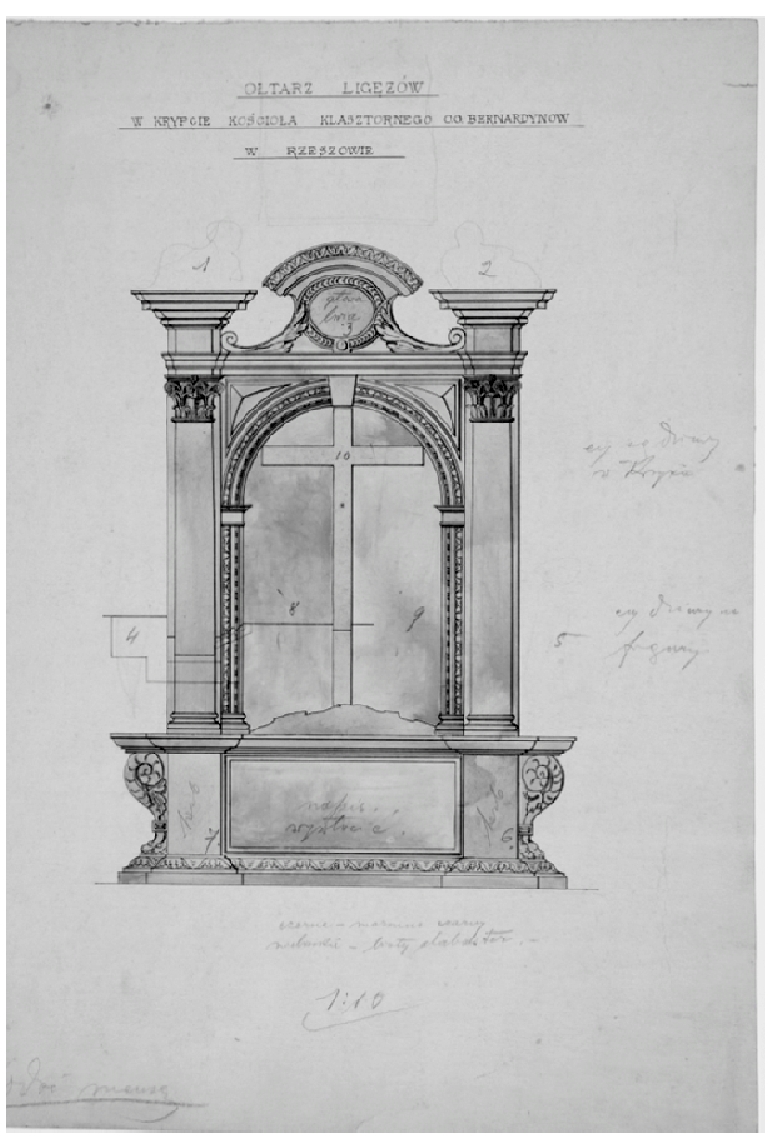

Rys. 1. Ołtarz z marmuru, Muzeum Narodowe w Krakowie $^{4}$

Fig. 1. The marble altar, National Museum in Krakow

\footnotetext{
${ }^{4}$ Zygmunt Hendel, Rzeszów - Kościół przy klasztorze OO. Bernardynów - Krypta grobowa Ołtarz z marmuru, 1900 rok, 46.8 x 35.2 cm, farba, papier, Zbiory Muzeum Narodowego w Krakowie, Dział III, nr inw. MNK III-PL-814.
} 
Mogła na tym zaważyć decyzja dotycząca przeniesienia ołtarza z podziemnej kaplicy i umieszczenia go w korytarzu północnym kościoła ${ }^{5}$. Sklepienie rzeczonego korytarza jest zawieszone na tyle nisko, że figury geniuszy, oznaczone na projekcie numerami 1 i 2 - najzwyczajniej nie mogły się tam pomieścić.

Kolejnym wartym uwagi projektem jest reprodukowany powyżej projekt przekształcenia tabernakulum, które znajduje się w kaplicy Matki Bożej Rzeszowskiej, który został najprawdopodobniej zrealizowany. Jest to ciekawe o tyle, że realizacja ta nie była do tej pory wiązana $\mathrm{z}$ wybitnym, krakowskim architektem. Dopisek u góry projektu (wariant II - nowy), pozwala w dużej mierze na ukonkretnienie powyższych przypuszczeń.

Tabernakulum dekoruje $\mathrm{w}$ części centralnej umieszczona na osi płycina zamknięta łukiem półokrągłym z uskokiem, z obu stron flankowana hermami z wyobrażeniami aniołów o wertykalnych, szpiczastych skrzydłach. Ponad dwoma, mocno rysującymi się, gzymsami oraz oddzielającą je przestrzenią dekorowaną płycinami, umieszczono wieńczącą całość, monstrancją podtrzymywaną przez dwoje symetrycznie zakomponowanych putt z finezyjnie rozwiniętymi skrzydłami. Repozytorium na hostię otacza płomienista gloria. Całość w sposób niezwykle subtelny i trafny koresponduje z charakterem wnętrza kaplicy (rys. 2).

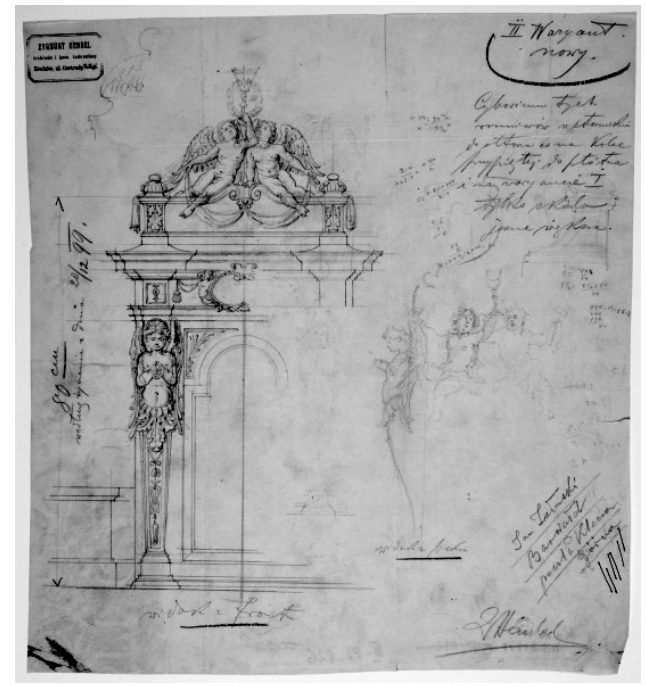

Rys. 2. Projekt cyborium, Muzeum Narodowe w Krakowie ${ }^{6}$

Fig. 2. The ciborium project, National Museum in Krakow

\footnotetext{
${ }^{5}$ Wojewódzki Urząd Konserwatora Zabytków w Rzeszowie, Karta Ewidencyjna Zabytków Architektury i Budownictwa, Kościót OO. Bernardynów w Rzeszowie, opr. J. Malczewski, 10.01.93, zał. nr 1.

${ }^{6}$ Zygmunt Hendel, Rzeszów - Kościół przy klasztorze OO. Bernardynów - Projekt cyborium - 2 rys.: "Widok z frontu"; "Widok z boku", 1900 rok, 40.3 x 37 cm, papier, Zbiory Muzeum Narodowego w Krakowie, Dział III, nr inw. MNK III-PL-826.
} 
To, czy Zygmunt Hendel jest także twórcą przebudowy mensy ołtarzowej w kaplicy Matki Boskiej Rzeszowskiej - oraz dekoracyjnego obramowania absydy mieszczącej cudowną figurę - wymaga dalszej weryfikacji - niemniej jednak zachowane projekty (nr inw. MNK III-PL-2087, nr inw. MNK III-PL835) (rys. 3 i 4) pozwalają na wysnucie takiej hipotezy oraz nakazują przebadanie stopnia ingerencji Hendla w oryginalny kształt ołtarza zwanego na projekcie: wielkim.

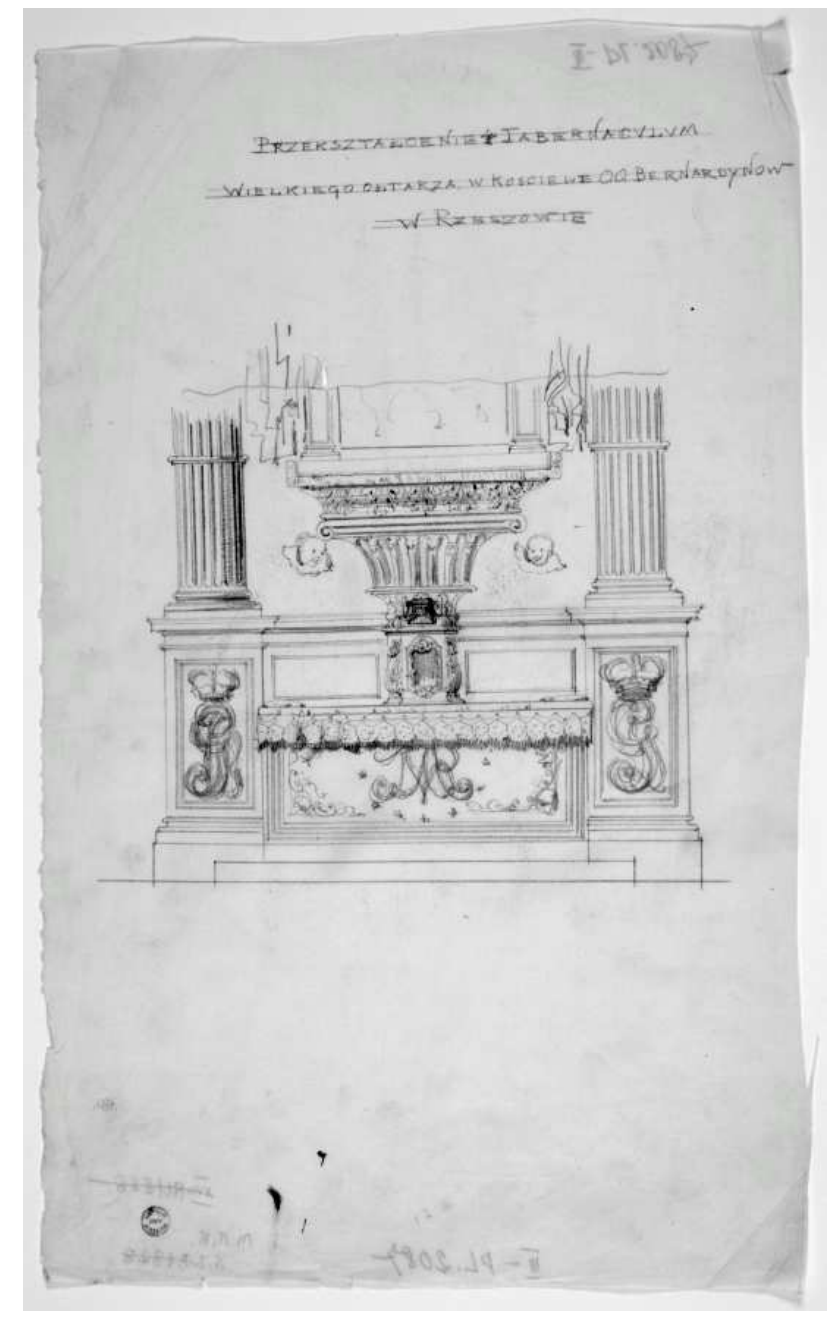

Rys. 3. Przekształcenie tabernakulum wielkiego ołtarza, Muzeum Narodowe w Krakowie ${ }^{7}$

Fig. 3. The transformation of the tabernacle of the great altar, National Museum in Krakow

\footnotetext{
${ }^{7}$ Zygmunt Hendel, Rzeszów - Kościół klasztorny OO. Bernardynów - Przekształcenie tabernakulum wielkiego ołtarza (sic!) - Ujęcie frontalne, 1900 rok, 44.5 x $27.3 \mathrm{~cm}$, ołówek, bibułka, Zbiory Muzeum Narodowego w Krakowie, Dział III, nr inw. MNK III-PL-2087.
} 


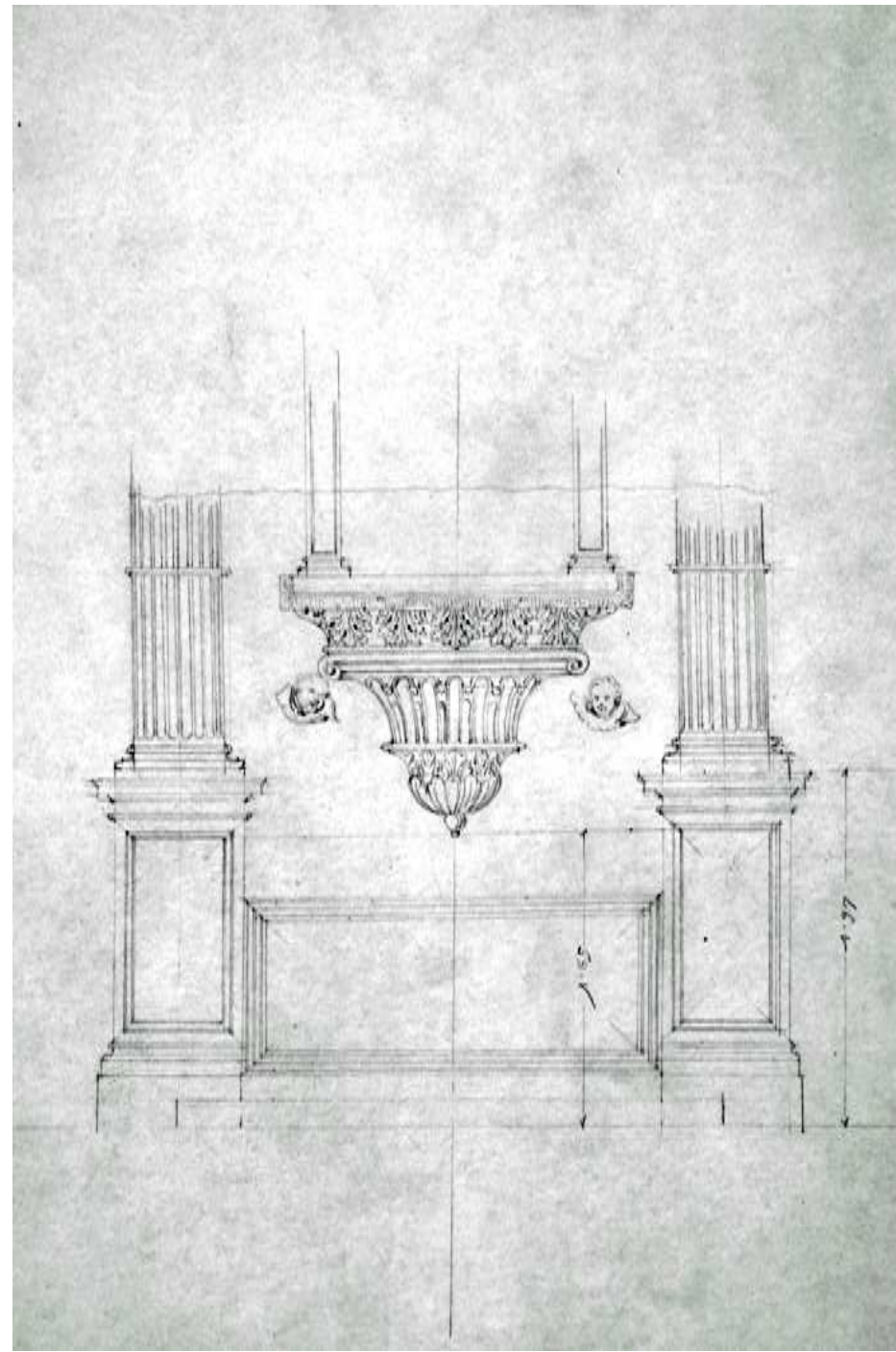

Rys. 4. Przekształcenie tabernakulum, Muzeum Narodowe w Krakowie ${ }^{8}$

Fig. 4. The transformation of the tabernacle, National Museum in Krakow

\footnotetext{
${ }^{8}$ Zygmunt Hendel, Rzeszów - Kościół klasztorny OO. Bernardynów - Przekształcenie tabernakulum [kaplica Matki Boskiej Rzeszowskiej - dopisek B.J.]- Projekt, 1900 rok, 56 x 40 cm, karton, Zbiory Muzeum Narodowego w Krakowie, Dział III, nr inw. MNK III-PL-835.
} 

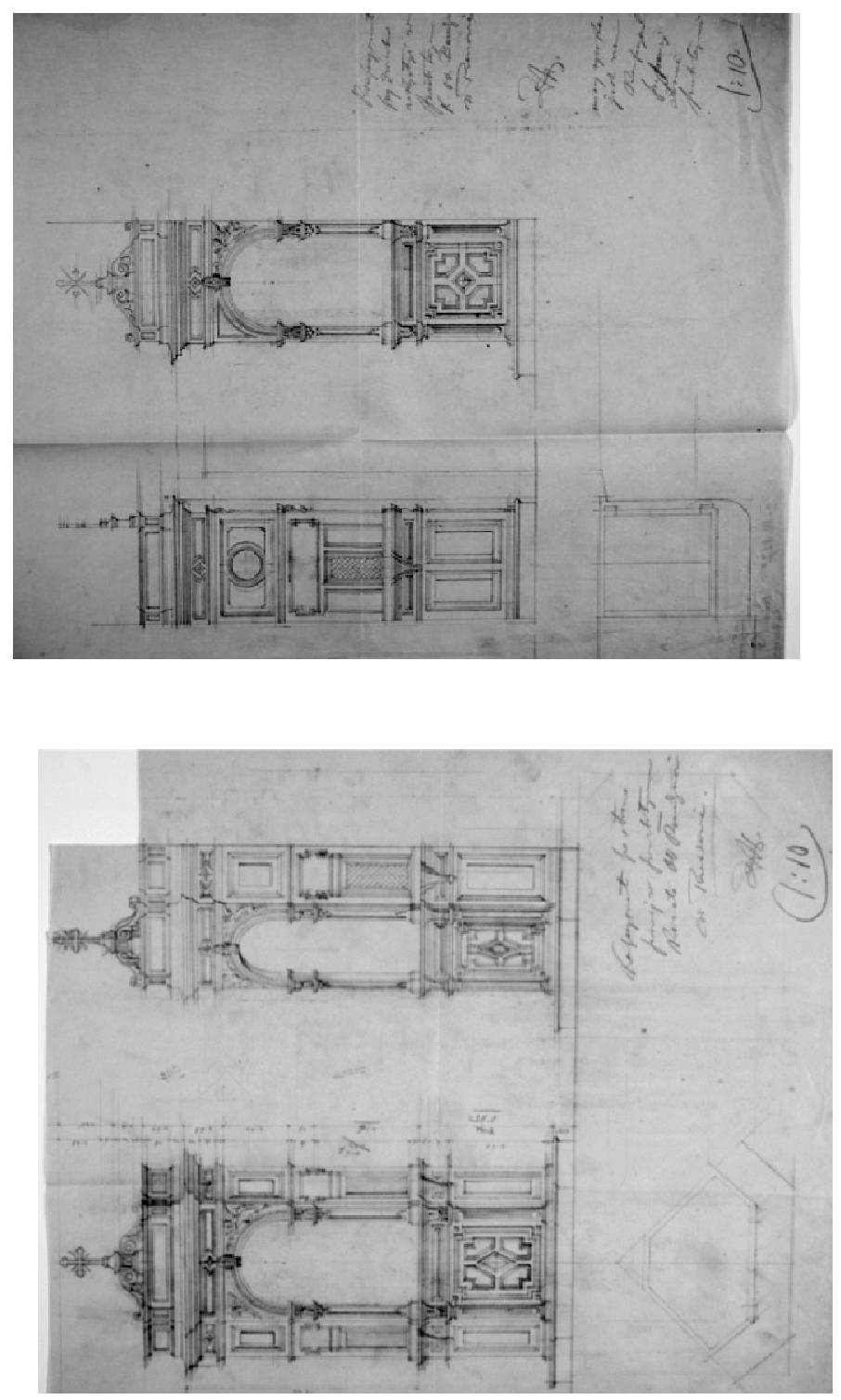

\footnotetext{
${ }^{9}$ Zygmunt Hendel, Rzeszów - Kościół przy klasztorze OO Bernardynów - Konfesjonał - 3 rys.: Widok z boku; Widok frontalny; Plan, 1900 rok, 62 x $50.5 \mathrm{~cm}$, papier, Zbiory Muzeum Narodowego w Krakowie, Dział III, nr inw. MNK III-PL-827.

${ }^{10}$ Zygmunt Hendel, Rzeszów - Kościół klasztorny OO. Bernardynów - Konfesjonał - 2 rys.: Widok frontalny; Ujęcie boczne, 1900 rok, 54.3 x $48.3 \mathrm{~cm}$, wymiary 3: 40.5 x $58.5 \mathrm{~cm}$, papier, Zbiory Muzeum Narodowego w Krakowie, Dział III, nr inw. MNK III-PL-2066.
} 
Następnymi projektami, z których przynajmniej jeden najprawdopodobniej został zrealizowany, acz w okrojonej wersji (brak dekoracyjnego zwieńczenia widocznego na projekcie), są projekty dwu konfesjonałów mających znaleźć się w obszarze prezbiterium. Jeden z nich usytuowany po prawej stronie prezbiterium posiadający numer MNK III-PL-2066 (rys. 5) znajduje się tam po dziś dzień. Drugiego natomiast nie udało się odnaleźć, ustalono natomiast, że żaden z konfesjonałów przekazanych do kościoła w Skępem w latach 70. XX wieku przez rzeszowskich Bernardynów - nie mógł być wykonany wg projektu o numerze MNK III-PL-827 (rys. 6). Został on zaprojektowany przez Hendla z zamiarem umieszczenia go przy drzwiach zakrystii w prezbiterium.

Skąd wiadomo, że to projekty realizacyjne nie zaś inwentaryzacyjne? Na obecnym etapie badań, które domagają się gruntownej weryfikacji w kontekście dokumentacji archiwalnej, jest parę przesłanek pozwalających na takie przypuszczenie. Pierwszą z nich jest zapisek samego architekta umieszczony na drugim z projektów. Architekt powołuje się w nim na dokładnie zwymiarowane proporcje zamieszczone na rys. 5 sugerując najprawdopodobniej wykonawcy - zastosowanie proporcji identycznych także i w tym przypadku. Kolejną i najważniejszą rzeczą jest geometryczna dekoracja płycin zdobiących obudowę siedziska - identyczna jak w przypadku obudowy klęczników stalli, których Hendel jest bezdyskusyjnym projektantem.

Ostatnim z projektów dotyczących wystroju świątyni bernardyńskiej w Rzeszowie jest projekt witraża (rys. 7). Pełen prostoty geometryczny wzór wypełniający tafle przeszklenia, urozmaicony został rozmieszczonymi w trzech piono-

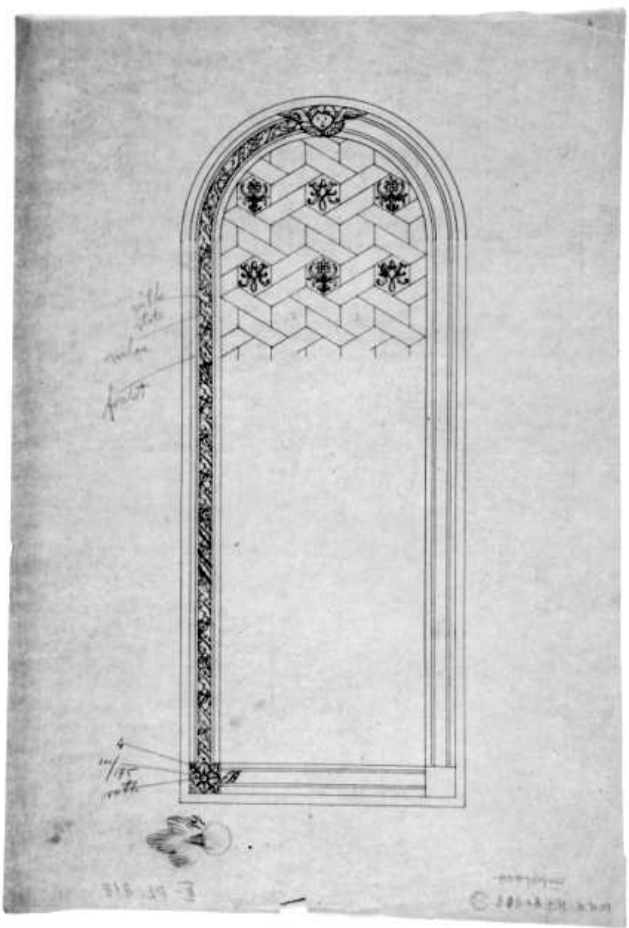

Rys. 7. Projekt oszklenia okna witrażem, Muzeum Narodowe w Krakowie ${ }^{11}$

Fig. 7. Design glazing stained glass windows, National Museum in Krakow

\footnotetext{
${ }^{11}$ Zygmunt Hendel, Rzeszów - Kościół przy klasztorze OO. Bernardynów - Projekt oszklenia okna witrażem, 1900 rok, 49.5 x $34 \mathrm{~cm}$, tusz, papier, nr inw. MNK III-PL-818; inne projekty przeszkleń (prezentujące podobne rozwiązanie), Zbiory Muzeum Narodowego w Krakowie, Dział III, nr inw. MNK III-PL-818.
} 
wych rzędach sześciokątami $\mathrm{z}$ wpisanymi weń monogramami maryjnymi naprzemian z motywem kwiatowym. Całości dopełnia dekoracyjna fitomorficza bordiura w kolorach żółcieni, złota, zieleni i fioletu (zapiski na projekcie). Główka cherubina umieszczona u góry na osi okna - to element stanowiący wspólny element wielu spośród projektów autorstwa Zygmunta Hendla, dotyczących wyposażenia wnętrza rzeszowskiej świątyni.

Zachowane projekty autorstwa $\mathrm{Z}$. Hendla związane $\mathrm{z}$ restauracją zespołu OO. Bernardynów w Rzeszowie w większości przypadków są dowodem szacunku konserwatora do substancji zabytkowej. Stylowe uzupełnienia elementów wystroju wnętrza cechuje historyczne podejście i pokora w doborze repertuaru środków wynikająca z podporządkowania się dyktaturze restaurowanego zabytku. Stanowią one pokłosie i wypadkową ogromnej wiedzy, powściągliwości i pietyzmu charakterystycznego dla krakowskiej szkoły konserwatorskiej.

\section{Literatura}

[1] Bogdalski Cz.: Pamiętnik kościoła i klasztoru OO. Bernardynów w Leżajsku, Kraków 1929.

[2] Fischinger A., Krukowski P.: Kościół Bernardynów w Rzeszowie, [w:] Studia renesansowe, t. 3, 1963.

[3] Gosztyła M., Jagieła B.: Reprezentatywne zabytki kultury materialnej Podkarpacia, Jarosław 2004.

[4] Hendel Z., Kopera F.: Kościół św. Idziego, „Biblioteka Krakowska”, Kraków $1905,29$.

[5] Hendel Z., Kopera F.: Resztki murów romańskich w kościele św. Jana w Krakowie, „Rocznik Krakowski”, 1907, T. 9.

[6] Kronika Klasztoru OO. Bernardynów, 1862 r.

[7] Kurowska E., Tokarski W.P. OFM: Bazylika Ojców Bernardynów w Rzeszowie. Przewodnik, Rzeszów 2009.

[8] Laskowski A.: Pałac Klobassy w Skołyszynie - niespełniony sen naftowego magnata, [w:] Dwór polski. Zjawisko historyczne i kulturowe, Warszawa 2000.

[9] Łuszczkiewicz W.: Klasztor leżajski i jego dzieła sztuki. Wrażenia z podróży, Kraków 1895.

[10] Malczewski J.: Dzieje Rzeszowa do 1914 roku, Rzeszów 1985.

[11] Pierwsze Sprawozdanie CK Szkoły Przemysłowej we Lwowie za rok szkolny 1892/93 (z rysunkami gmachu szkolnego), Lwów 1893.

[12] Stępień P. M.: Hendel Zygmunt, [w:] Polski słownik biograficzny konserwatorów zabytków, red. Henryk Kondziela, Hanna Krzyżanowska, z. 2, Poznań, Wydaw. Poznańskie 2006.

[13] Wojewódzki Urząd Ochrony Zabytków w Rzeszowie: Karta Ewidencyjna Zabytków Architektury i Budownictwa, Kościół OO. Bernardynów w Rzeszowie, opr. J. Malczewski, 10.01.93, zał. nr 1. 
[14] Zbiory Wojewódzkiego Urzędu Ochrony Zabytków w Rzeszowie: Dokumentacja Konserwatorska, Rzeszów - ołtarz główny kościoła OO. Bernardynów w Rzeszowie, opr. S. Juszczak, Rzeszów 1996.

[15] Zygmunt Hendel, [w:] Polski Słownik Biograficzny konserwatorów zabytków, red. Kondziela H., Krzyżanowska H., Poznań 2006.

\section{CONSEVATION PROJECTS IN THE BERNARDINE CHURCH IN RZESZÓW BY ZYGMUNT HENDEL}

\section{S u m m a r y}

The actions of Hendel preceding the restoration works at the complex of Friars Minor of the Observance in Rzeszów as well as his position of the restorer in the district of Tarnów and Rzeszów constituted the best legitimisation of an architect and constituted the reasons of hiring him as the manager of the works on the complex of Friars Minor of the Observance in Rzeszów.

Resulting from the retained projects, it was a challenging and huge scale undertaking. Hendel combined the studies and restoration of the monuments of architecture with architectural creativity in his professional activity. He mostly expressed himself in form of eclectics. Part of his numerous projects was not implemented due to various circumstances. In the works on historic objects, the direction of restoration was prevailing, along with a rather broad differentiation of the kind and level of intervention - from reserved, limited compliments of the historic substance (which underwent restoring works within the existing state of knowledge and technology development) to the profound reconstruction and expansion of the object.

Below, there are significant restoring and project works and their specificity described.

While describing the projects which constitute the concept of restoration at the complex of Friars Minor of Observance in Rzeszów, which were implemented and those which were not implemented, the authors discuss the example of Saint Cross altar, tabernacle in the chapel of Mother of God from Rzeszów, altar stone in the Chapel of Mother of God from Rzeszów, confessionals. The project of the stained glass window was also discussed. The aim of the article is an attempt of analysing the assumed concepts of restoring the complex of Friars Minors of Observance in Rzeszów by the architect of Cracow - Zygmunt Hendel. The in-depth characteristics of restoring projects from the first decade of the 19th century was performed on the basis of the project documentation coming from the resources of the National Museum in Cracow. It allows us to deepen knowledge of both the history of the discussed monument and its history and development of restoring monuments on the area of Galicia in the period of autonomy.

Keywords: architectural monument, church, monastery, architect, renovation of monuments, Galicia autonomy

Przestano do redakcji: $19.12 .2014 r$.

Przyjęto do druku: 22.06.2015 r.

DOI:10.7862/rb.2015.43 